\title{
The impact of recent vincristine on human hematopoietic progenitor cell collection in pediatric patients with central nervous system tumors
}

\author{
Laura Cooling, ${ }^{1}$ Melissa Bombery, ${ }^{1}$ Sandra Hoffmann, ${ }^{1}$ Robertson Davenport, ${ }^{1}$ Patricia Robertson, ${ }^{2,3}$ \\ and John E. Levine $e^{3,4,5}$
}

BACKGROUND: Central nervous system (CNS) malignancies represent $20 \%$ of all childhood cancers. To improve outcomes in infants and children with high-risk disease, treatment can include adjuvant chemotherapy and early autologous peripheral blood human progenitor cell collection (AHPCC), followed by high-dose chemotherapy and stem cell rescue. In many protocols, postoperative chemotherapy includes the administration of weekly vincristine (VCR) between induction chemotherapy cycles, regardless of scheduled AHPCC. We observed anecdotal AHPCC failures in children receiving midcycle VCR (MC-VCR).

STUDY DESIGN AND METHODS: The study was an 8-year retrospective chart review of all children with a CNS malignancy and who underwent AHPCC. Information included patient demographic and clinical data, mobilization regimen, VCR administration, product yields, infusion toxicity, and patient charges. Data were analyzed relative to MC-VCR administration. Graphics and statistical analysis (t-test, chi-square, linear regression) were performed with commercial software.

RESULTS: Twenty-four patients and 47 AHPCCs were available for analysis. Nine patients $(37 \%)$ received MC-VCR within 7 days of scheduled AHPCC. MC-VCR was associated with delayed marrow recovery (17.9 days vs. 14.9 days, $p=0.0012)$, decreased median peripheral CD34 counts $\left(75 \times 10^{6}\right.$ CD34/L vs. $352 \times 10^{6}$ CD34/L, $p=0.03$ ), decreased median CD34 yields $\left(2.4 \times 10^{6} \mathrm{CD} 34 / \mathrm{L}\right.$ vs. $\left.17.8 \times 10^{6} \mathrm{CD} 34 / \mathrm{kg}, \mathrm{p}=0.08\right)$, more AHPCCs per mobilization (2.9 vs. 1.1, $p=0.01$ ), and an increased rate of remobilization (33\% vs. $6 \%$ ). Mean patient charges were $2.5 \times$ higher in patients receiving MC-VCR than controls $(p=0.01)$. CONCLUSION: MC-VCR should be withheld before scheduled AHPCC to optimize CD34 collection.

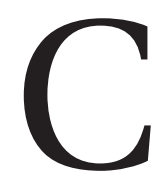

entral nervous system (CNS) malignancies are the second most common cancer in children, accounting for $20 \%$ of all childhood cancers. ${ }^{1}$ In the United States alone, there are approximately 4200 new cases diagnosed each year with the highest incidence in children less than 5 years of age. ${ }^{1}$ Astrocytoma, primitive neuroectodermal tumors (PNETs) including medulloblastoma, and ependymoma are the most frequent pediatric CNS cancers, with 5-year survival rates ranging from $40 \%$ to $80 \%{ }^{1-4}$ Poor prognostic factors include a young age ( $<3-5$ years), macrometastases, a higher residual tumor burden after resection, tumor location, unfavorable tumor histology, or genetics. ${ }^{2,3,5,6}$ Atypical teratoid rhabdoid tumors (ATRTs) have a particularly poor prognosis, with a median survival of only 16 months. ${ }^{7}$

ABBREVIATIONS: AHPCC(s) = autologous peripheral blood human progenitor cell collection(s); ATRT(s) = atypical teratoid rhabdoid tumor(s); $\mathrm{CBC}=$ complete blood count; $\mathrm{CNS}=$ central nervous system; $\mathrm{COG}=$ Children's Oncology Group; ICE = ifosamide, cisplatin, and etoposide; MC-VCR = midcycle vincristine; $\operatorname{PNET}(\mathrm{s})=$ primitive neuroectodermal tumor(s); $\mathrm{VCR}=$ vincristine.

From the ${ }^{1}$ Department of Pathology, the ${ }^{2}$ Department of Neurology, the ${ }^{3}$ Department of Pediatrics and Communicable Disease, the ${ }^{4}$ Department of Bone Marrow Transplantation, and the ${ }^{5}$ Department of Internal Medicine, University of Michigan, Ann Arbor, Michigan.

Address reprint requests to: Laura Cooling, MD, MS, University of Michigan Hospitals, 2F225 UH-Blood Bank, 1500 East Medical Center Drive, Ann Arbor, MI 48109-0054; e-mail: lcooling@med.umich.edu.

Received for publication March 26, 2013; revision received December 12, 2013, and accepted December 16, 2013.

doi: $10.1111 /$ trf.12574

(C) $2014 \mathrm{AABB}$

TRANSFUSION 2014;54:2004-2014. 
Standard therapy for pediatric CNS tumors consists of early surgical resection and radiotherapy, usually accompanied by adjuvant chemotherapy. ${ }^{2-4}$ Radiotherapy is the mainstay of treatment in older children, with $55 \%$ to $80 \%$ of medulloblastoma patients disease free after 5 years. ${ }^{2,8}$ Radiation is typically withheld, however, in very young children ( $\leq 3$ years) due to the risk of long-term, progressive neuropsychiatric sequlae. ${ }^{2}$ As a consequence, adjuvant chemotherapy has been employed to delay or avoid radiotherapy in this population., ${ }^{2,49}$ Several clinical trials have shown that most patients, regardless of age, can benefit from adjuvant chemotherapy. ${ }^{2,3,8}$ In medulloblastoma, the addition of adjuvant chemotherapy has increased the overall 5-year survival of standard risk patients (70\%-87\%), infants (46\%-86\%), and patients with high-risk disseminated disease (44\%-60\%). ${ }^{3}$ In many protocols, adjuvant chemotherapy employs several courses of multiagent chemotherapy and weekly vincristine (VCR) ${ }^{2,3,8}$

To further improve outcomes in infants and other high-risk patients, more recent studies have added highdose, myeloablative chemotherapy and autologous stem cell rescue. ${ }^{3,4,10}$ Patients generally undergo autologous peripheral blood human progenitor cell collection (AHPCC) after their first or second cycle of induction chemotherapy, followed later by one to three cycles of highdose chemotherapy and stem cell rescue. ${ }^{10-18}$ Because VCR is considered "marrow sparing" at the doses used clinically, ${ }^{19}$ most protocols stipulate the continued administration of weekly VCR between induction chemotherapy cycles (midcycle VCR [MC-VCR]), regardless of scheduled AHPCC. ${ }^{12,13,15-18}$ We anecdotally observed several poor AHPCC in young children who had received scheduled MC-VCR 1 week before AHPCC. To determine whether MC-VCR was a risk factor for poor CD34 mobilization and collection, we performed an 8-year retrospective review of all pediatric patients with a CNS malignancy and who underwent AHPCC at our institution.

\section{MATERIALS AND METHODS}

\section{Patients and study design}

The study was an 8-year retrospective study of all pediatric patients referred for AHPCC at the University of Michigan from January 2004 through December 2011. Inclusion criteria included an age less than 21 years, a histologic diagnosis of a CNS malignancy, and at least one AHPCC. All clinical trial treatment protocols, AHPCCs, and data analysis were approved by the institutional review board of the University of Michigan.

Patient demographic data included patient age, sex, weight, histologic diagnosis, prior therapy, mobilization regimen, dates of VCR administration, number of mobilization cycles, number of hospital days, and type of venous access. Pharmacology data included drugs known to decrease VCR clearance. ${ }^{19}$ Patient laboratory studies included the preprocedure complete blood count (CBC), white blood cell (WBC) differential, and peripheral CD34 count (\%CD34, CD34 $\left.\times 10^{6} / \mu \mathrm{L}\right)$. For patients who received MC-VCR, the WBC and platelet (PLT) count on the day of VCR administration was recorded, if available. Procedurerelated information included the first day of AHPCC after chemotherapy, the total number of AHPCCs, cell yield (mononuclear cells [MNCs], CD34, granulocytes) per procedure, total cell yield per mobilization cycle, and need for plerixafor salvage. For remobilized patients, each mobilization cycle was counted as a separate event. Infusion records were reviewed for patient age, weight, infusion volume, cell dose, and adverse reactions for each infusion. Adverse reactions were graded according to the CTC-NCI classification. ${ }^{20}$ If more than one symptom was recorded, the highest grade was recorded for the infusion.

\section{Adjuvant chemotherapy}

Most patients were enrolled, or treated off-study, in one of three multi-institutional clinical trials for pediatric CNS tumors: Children's Oncology Group (COG)-99701, COG99703, and COG-ACNS0333 (Table 1). ${ }^{16-18}$ Patients treated per COG-99701 received 6 weeks of craniospinal radiation therapy with daily carboplatin, followed by adjuvant therapy with cyclophosphamide, cisplatin, and VCR (Days 0 and +7 ). Patients treated on COG-99703 received three cycles of induction chemotherapy with cisplatin, cyclophosphamide, etoposide, and weeklyVCR (Days $0,+7$, and +14 ) with AHPCC after their first cycle of induction chemotherapy. ${ }^{17}$ ATRT patients enrolled in COG-ACNS0333 received three cycles of induction therapy with cyclophosphamide, etoposide, cisplatin, methotrexate, and weekly VCR (Days 0, +8, and +15), with AHPCC scheduled after their first round of induction therapy ${ }^{18} \mathrm{VCR}$ administered 7 to 15 days after the first day of each chemotherapy cycle (Day 0) was classified as MC-VCR.

Three patients were treated with four to eight cycles of cisplatin, lomustine, and weekly $\mathrm{VCR},{ }^{9}$ including two patients who underwent AHPCC after eight cycles. One patient initially treated on COG-99701 (one cycle) subsequently received one cycle of ifosamide, cisplatin, and etoposide (ICE) before AHPCC. ${ }^{21}$ One patient was treated with temozolomide. ${ }^{22}$ One patient underwent AHPCC after receiving 8 weeks of radiation and VCR only. ${ }^{13}$

\section{Stem cell mobilization}

There were a total of 28 mobilizations in 24 patients (Fig. 1): Four patients required remobilization due to poor collection yields. The majority $(22 / 24)$ of patients were collected after chemotherapy and granulocyte-colonystimulating factor (G-CSF). Patients treated according to COG protocols were generally collected after their first or 


\begin{tabular}{|c|c|c|c|c|}
\hline Demographics & All patients & MC-VCR & No VCR & $p$ value \\
\hline Number of patients* & $24^{*}$ & 9 & 16 & \\
\hline Sex (male/female) & $13 / 11$ & $5 / 4$ & 9/7 & 0.97 \\
\hline Age (years) $\dagger$ & $5.4 \pm 5.5(3,0.9-19)$ & $4.5 \pm 3.5(3,0.9-11)$ & $5.7 \pm 6.2(2.5,0.9-19)$ & 0.62 \\
\hline$\leq 3$ years & $15^{\star}(62.5)$ & $6^{*}(66.7)$ & $10^{*}(62.5)$ & 1.00 \\
\hline Weight $(\mathrm{kg}) \dagger$ & $23.8 \pm 21.2(15.2,7.8-100)$ & $19 \pm 7.4(15.6,10-31)$ & $26.2 \pm 25.3(14.9,7.8-100)$ & 0.30 \\
\hline \multicolumn{5}{|l|}{ Diagnosis† } \\
\hline Medulloblastoma & $12(50)$ & $3(33)$ & $9(56)$ & 0.28 \\
\hline ATRT & $6(25)$ & $2(22)$ & $4(25)$ & 0.88 \\
\hline PNET & $2(8)$ & $1(11)$ & $1(6)$ & \\
\hline Astroblastoma & $1(4)$ & $1(11)$ & 0 & \\
\hline Medulloepithelioma* & $1^{*}$ & 1 & 1 & \\
\hline Ependymoma & 1 & 0 & 1 & \\
\hline Ganglioma & 1 & 1 & 0 & \\
\hline Time from diagnosis (months) & $5.3 \pm 9.1(2.5,0.5-44)$ & $3.3 \pm 1.6(3.5,1-5.7)$ & $6.6 \pm 11.5(2,0.5-44)$ & 0.25 \\
\hline Prior radiotherapy* & $11^{*}$ & 5 & 7 & 0.58 \\
\hline Carboplatin & 3 & 2 & 1 & 0.08 \\
\hline \multicolumn{5}{|l|}{ Adjuvant chemotherapy } \\
\hline COG-99701 & 3 & 2 & 1 & 0.22 \\
\hline COG-99703 & 14 & 6 & $8 \ddagger$ & 0.25 \\
\hline COG-ACNS0333 & 3 & 0 & 3 & 0.17 \\
\hline Cisplatin, lomustine, VCR & 3 & 1 & 2 & 0.92 \\
\hline ICE & 1 & 0 & $1 \ddagger$ & \\
\hline Temozolomide & 1 & 0 & 1 & \\
\hline VCR only & 1 & 0 & 1 & \\
\hline \multicolumn{5}{|c|}{$\begin{array}{l}\text { * One patient ( } 3 \text { years old, medulloepithelioma) was originally collected after receiving MC-VCR. He was remobilized with cyclophosphamide } \\
\text { and G-CSF without additional MC-VCR. This patient also received radiation. } \\
\text { † Results reported as mean } \pm \text { SD (median, range) or number (\%). } \\
\text { † One patient was initially treated per COG-99703 (Cycle 1). Subsequent chemotherapy was changed to ICE (Cycle 2). This patient under- } \\
\text { went AHPCC after Cycle } 2 \text {. } \\
\text { COG-99701 = cyclophosphamide, VCR, with or without cisplatin; COG-99703 = cisplatin, cyclophosphamide, etoposide, VCR; COG- } \\
\text { ACNS0333 = cisplatin, cyclophosphamide, etoposide, VCR, methotrexate; NA = not applicable. }\end{array}$} \\
\hline
\end{tabular}

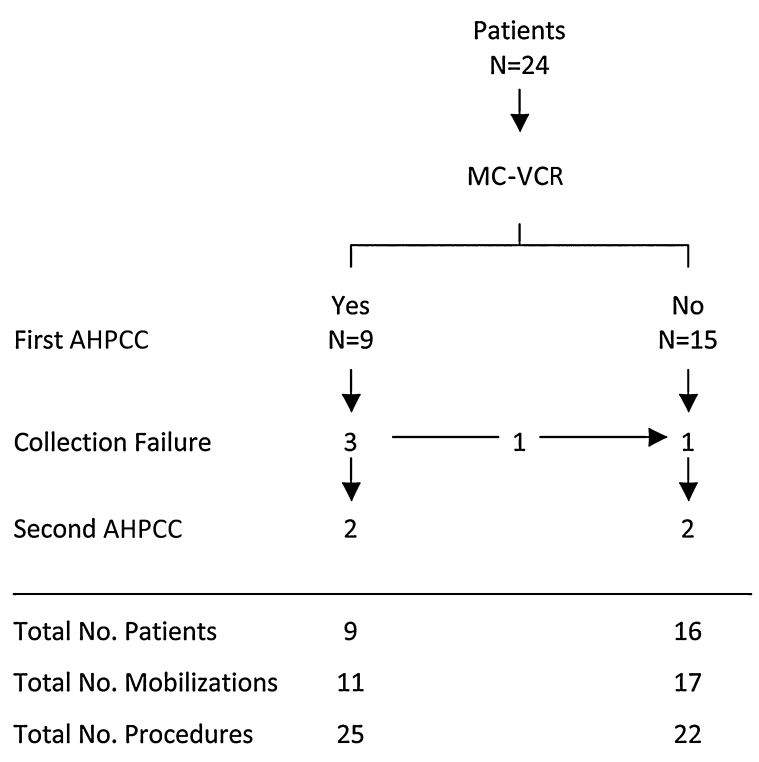

Fig. 1. Study schematic of AHPCC and MC-VCR administration. Note that four patients required remobilization, including three patients who initially received MC-VCR.

second round of induction chemotherapy. Three patients were collected after either ICE (one patient) or cyclophosphamide $\left(4 \mathrm{gm} / \mathrm{m}^{2}\right.$, two patients). All patients received G-CSF $(10 \mu \mathrm{g} / \mathrm{kg})$ for 4 to 5 days before AHPCC. COG patients often received low-dose G-CSF ( $5 \mu \mathrm{g} / \mathrm{kg}$ ) initially, which was increased to standard dose $(10 \mu \mathrm{g} / \mathrm{kg})$ after evidence of marrow recovery (absolute neutrophil count $>500-1000$ ). One MC-VCR patient with delayed marrow recovery received a short course of high-dose G-CSF $(20 \mu \mathrm{g} / \mathrm{kg})$. Plerixafor was administered to two patients after poor collection yields on Day $1 .{ }^{23}$ Plerixafor $(0.24 \mathrm{mg} /$ $\mathrm{kg}$ ) was administered the evening before AHPCC.

Two patients were mobilized with growth factor only. One patient received G-CSF (10-15 $\mu \mathrm{g} / \mathrm{kg})$, supplemented with plerixafor on Day 2. A second patient underwent a remobilization with G-CSF $(10 \mu \mathrm{g} / \mathrm{kg})$ and granulocyte-monocyte-colony-stimulating factor (GMCSF; $500 \mu \mathrm{g} / \mathrm{kg}$ ). Because growth factor-only mobilization is less efficient than chemotherapy mobilization, these patients and collections were often analyzed separately (Table 2). ${ }^{24,25}$

\section{Leukapheresis}

All patients were evaluated and medically cleared for AHPCC according to institutional and study guidelines. Parental consent for leukapheresis and infectious disease testing was obtained on the first day of collection. All patients had a preprocedure peripheral CBC and WBC differential before each AHPCC. Most patients also had a peripheral CD34 count drawn before the first AHPCC. The 


\begin{tabular}{|c|c|c|c|c|}
\hline Measure & All patients & MC-VCR & No VCR & $p$ value \\
\hline Number of mobilization cycles & 28 & 11 & 17 & \\
\hline Patients remobilized & $4(16)$ & $3(33)$ & $1(6)$ & 0.08 \\
\hline \multicolumn{5}{|l|}{ Mobilization regimen } \\
\hline Chemotherapy with G-CSF & $26(93)$ & 11 & 15 & 0.21 \\
\hline Treatment-specific & 24 & 11 & 13 & 0.18 \\
\hline Cyclophosphamide & 2 & 0 & 2 & 0.18 \\
\hline Growth factor only & $2(7)$ & 0 & 2 & 0.21 \\
\hline G-CSF & 1 & 0 & 1 & \\
\hline G-CSF plus GM-CSF & 1 & 0 & 1 & \\
\hline G-CSF dose $(\mu \mathrm{g} / \mathrm{kg})$ & $10.8 \pm 2.3$ & $9.8 \pm 3.1$ & $10.7 \pm 1.9$ & 0.65 \\
\hline \multicolumn{5}{|l|}{ Plerixafor salvage } \\
\hline Number of patients & 3 & 2 & $1 \dagger$ & 0.24 \\
\hline Total number of doses & 9 & 7 & 2 & \\
\hline \multicolumn{5}{|l|}{ Blood counts (Day 1) } \\
\hline WBC $\left(\times 10^{9} / \mathrm{L}\right)$ & $19.1 \pm 18$ & $13.5 \pm 21.1$ & $22.7 \pm 21.1$ & 0.13 \\
\hline$\%$ MNCs & $22.4 \pm 15.6$ & $27.3 \pm 18.9$ & $19.1 \pm 12.5$ & 0.19 \\
\hline$\%$ CD34 (median) & $2.2 \pm 0.6(0.98)$ & $2.3 \pm 1.0(0.88)$ & $2.5 \pm 0.8(1.5)$ & 0.90 \\
\hline CD34 × 106/L, \pm SEM (median) & $213.4 \pm 61.9(78.6)$ & $266.3 \pm 145(74.9)$ & $280.2 \pm 58.4(278)$ & 0.09 \\
\hline Chemotherapy plus G-CSF (median) & $285 \pm 78.9$ (222.2) & $266.3 \pm 145(74.9)$ & $331.7 \pm 57.0(352)$ & 0.03 \\
\hline Growth factor only (median) & & & $20.7 \pm 10.9(18.8)$ & $0.004 \S$ \\
\hline \multicolumn{5}{|l|}{ Collection } \\
\hline Day to collection $\ddagger$ & $16 \pm 2.4$ & $17.9 \pm 2.0$ & $14.9 \pm 1.9$ & 0.0012 \\
\hline Total number of procedures & 47 & 25 & 22 & \\
\hline Chemotherapy plus G-CSF & & 25 & 17 & \\
\hline Growth factor only & & 0 & 5 & \\
\hline Number of procedures per patient & $1.9 \pm 1.7$ & $2.9 \pm 2.3$ & $1.3 \pm 0.8$ & 0.025 \\
\hline Chemotherapy plus G-CSF & $1.8 \pm 1.6$ & $2.9 \pm 2.3$ & $1.1 \pm 0.4$ & 0.01 \\
\hline Growth factor only & & & $2.5 \pm 1.5$ & $0.03 \S$ \\
\hline \multicolumn{5}{|l|}{ Product yield } \\
\hline$\%$ MNCs & $43.1 \pm 20.5$ & $39.2 \pm 15$ & $47.7 \pm 25.1$ & 0.18 \\
\hline MNCs $\times 10^{8} / \mathrm{kg}$ & $2.8 \pm 0.3$ & $2.5 \pm 0.3$ & $3.2 \pm 0.6$ & 0.28 \\
\hline$\%$ CD34 & $2.2 \pm 0.4$ & $1.6 \pm 0.5$ & $3.0 \pm 0.5$ & 0.06 \\
\hline CD34 × 10\%/kg (median) & $16.5 \pm 3.5(4.0)$ & $12.3 \pm 5.1(2.4)$ & $21.0 \pm 4.6(17.8)$ & 0.21 \\
\hline Chemotherapy plus G-CSF (median) & $18.1 \pm 3.8(4.9)$ & $12.3 \pm 5.1(2.4)$ & $25.1 \pm 5.2(21.5)$ & 0.08 \\
\hline Growth factor only & & & $2.5 \pm 1.3$ & $0.004 \S$ \\
\hline \multicolumn{5}{|l|}{ Total yield per mobilization } \\
\hline MNCs $\times 10^{8} / \mathrm{kg}$ & $4.4 \pm 0.7$ & $5.1 \pm 1.3$ & $3.2 \pm 0.7$ & 0.38 \\
\hline $\mathrm{CD} 34 \times 10^{6} / \mathrm{kg}$ & $30.3 \pm 5.1$ & $28.9 \pm 5.3$ & $32.7 \pm 11.3$ & 0.76 \\
\hline \multicolumn{5}{|c|}{$\begin{array}{l}\text { * Results reported as number (\%) or mean } \pm \text { SD except where noted. } \\
\text { † Patient mobilized with G-CSF only. } \\
\text { † Number of days since the last round of induction or mobilization chemotherapy. } \\
\S \text { Growth factor versus chemotherapy mobilized (no-VCR) controls. }\end{array}$} \\
\hline
\end{tabular}

need for mild sedation during AHPCC was determined by the transplant physician. Patients who required a red blood cell (RBC) or whole blood prime were medicated with an antipyretic and antihistamine. RBCs were leukoreduced before storage and irradiated per institutional policy.

All patients were collected on a cell separator (COBE Spectra, Gambro BCT, Lakewood, CO) using the WBC collection set. ${ }^{24}$ Central venous catheters were used for venous access in all patients. MNCs were collected by continuous-flow centrifugation with a blood-plasma interface manually adjusted to a $1 \%$ to $2 \%$ hematocrit, a mean inlet volume of $1 \mathrm{~mL} / \mathrm{kg} / \mathrm{min}$, and a collection volume of $1.0 \mathrm{~mL} / \mathrm{min}$. For patients more than $10 \mathrm{~kg}$, blood was anticoagulated with ACD-A at a whole blood : ACD-A ratio of $12: 1$. To mitigate against dilutional anemia and hypotension, a RBC prime was used if the extracorporeal volume was greater than $10 \%$ of the patient's blood volume. Patients received prophylactic calcium gluconate to prevent citrate toxicity.

For very small children $(<10 \mathrm{~kg})$, AHPCC was performed using a reconstituted whole blood prime and heparin anticoagulation (30 units/kg). Heparin anticoagulation was monitored by activated clotting time (therapeutic, $180-220 \mathrm{sec})$. To prevent clotting of the product, ACD-A (10\% final product volume) was manually added to the final product.

A total of three blood volumes were processed per AHPCC. For patients more than $40 \mathrm{~kg}, 200 \mathrm{~mL}$ of plasma was collected concurrently for processing. For patients 20 to $40 \mathrm{~kg}, 100 \mathrm{~mL}$ of plasma was collected. No plasma was collected for children with less than $10 \mathrm{~kg}$ body weight.

The desired target CD34 yield for the vast majority $(22 / 24)$ of patients was 15 million CD34/kg or sufficient CD34 cells for three autologous hematopoietic progenitor cell (HPC) infusions at $5 \times 10^{6} \mathrm{CD} 34 / \mathrm{kg}$ per infusion. The 
protocol minimum CD34 target dose was 6 million $\mathrm{CD} 34 / \mathrm{kg}$ or $2 \times 10^{6} \mathrm{CD} 34 / \mathrm{kg}$ per HPC infusion. ${ }^{17,18}$ In one patient, the CD34 target was 8 million CD34/ $\mathrm{kg}$, for four infusions at $2 \times 10^{6} \mathrm{CD} 34 / \mathrm{kg}$ each. One patient was collected for a single autotransplant of $3 \times 10^{6} \mathrm{CD} 34 / \mathrm{kg} .{ }^{24} \mathrm{All}$ patients were collected daily until they reached their CD34 target yield or unless terminated by the apheresis and transplant physician due to poor or falling collection yields.

\section{Product analysis}

Volume, WBC count, WBC differential (\%MNCs, MNCs/ $\mathrm{kg})$, and CD34 counts (\%CD34, CD34/kg) were determined on all products. CD34 yields and cell viability were determined by flow cytometry as recommended by the International Society of Hematology and Graft Engineering (ISHAGE). ${ }^{26}$ Colony-forming assays were not performed per institutional policy. Sterility testing of each product was performed before and after processing using the USP culture method per 21 CFR $610.12 .{ }^{27}$ Cells were volume adjusted and divided, as appropriate, into sufficient number of units to support multiple HPC rescues. Cells were frozen in $10 \%$ dimethyl sulfoxide and stored in the vapor phase of liquid nitrogen until use.

\section{Cost analysis}

The financial impact of MC-VCR on AHPCC costs was performed using patient charges for leukapheresis, cryopreservation, and need for in-patient hospitalization. Data were limited to patients mobilized with chemotherapy and G-CSF. Patient charges for all services were calculated at the 2012 fiscal year rate. Leukapheresis costs included the technical charge for the procedure and preprocedure laboratories (CBC, WBC differential, peripheral CD34 count). Cell therapy laboratory charges associated with cryopreservation included cell processing, freezing, cell analysis (product counts, flow cytometry), and sterility cultures. Hospital charges were based on the daily rate for an acute care bed. For patients already hospitalized for other reasons, only the days in which the patient underwent AHPCC were included in the cost analysis. G-CSF charges were not included due to ambiguous or incomplete records from outside facilities regarding the exact dates of G-CSF initiation, as well as the date of any changes in G-CSF dosage that may have occurred before AHPCC. ${ }^{17,18}$ Plerixafor costs were calculated using the in-patient or direct cost rate. Because plerixafor is distributed as a single-use vial, plerixafor costs were charged per vial regardless of the amount of plerixafor used per injection.

Mean patient charges for leukapheresis, laboratory, and hospitalization were analyzed relative to MC-VCR. Because remobilization was considered a consequence and complication of a failed initial collection series, the additional costs of a second AHPCC series were added and assigned to the first AHPCC (Fig. 1, $\mathrm{n}=4$ ). Mean patient charges were calculated based on the sum total of all costs divided by the number of patients. Due to the small number of patients requiring plerixafor salvage, total charges were calculated with and without plerixafor.

\section{Statistical analysis}

Quantitative data were reported as mean \pm standard deviation (SD) except where noted. Variables with wide interpatient values were reported as mean, median, and range. Quantitative data were compared relative to MC-VCR administration by t test. Categorical data were analyzed by chi-square using computer software (EpiInfo, Centers for Disease Control and Prevention, Atlanta, GA). Graphics and $t$ tests were performed with commercial software (Kaleidograph, Synergy Software, Reading, PA). A $\mathrm{p}$ value of less than 0.05 was considered significant.

\section{RESULTS}

\section{Patient demographics}

Between 2004 and 2011, a total of 24 pediatric CNS patients underwent AHPCC (Fig. 1). Patients ranged in age from 10 months to 19 years of age. The majority of patients $(15 / 24,62 \%)$ were 3 years or younger at time of AHPCC. The most frequent diagnoses were medulloblastoma (50\%, Table 1), followed by ATRT and PNET. The mean time between diagnosis and AHPCC was 5.3 months, with $85 \%$ of patients undergoing AHPCC within 6 months of diagnosis.

All patients underwent surgical resection, followed by chemotherapy, before referral for AHPCC. Most patients (22/24) had received multiagent therapy with VCR, cisplatin, cyclophosphamide, etoposide, or lomustine (Table 1). For patients enrolled in three COG protocols, $70 \%$ underwent AHPCC after their first cycle of induction chemotherapy. Ten patients received radiotherapy before AHPCC. ${ }^{28,29}$ Most patients (80\%) receiving radiotherapy were more than 3 years of age (10.4 \pm 4.9 years).

\section{MC-VCR administration}

VCR is administered weekly per COG-99701 (Days 0 and +7), COG-99703 (Days 0 and +7), and COG-ACNS0333 (Days $0,+8$, and +15 ). ${ }^{16-18}$ Nine patients received MC-VCR within 1 week of scheduled AHPCC per protocol. Seven patients received a single scheduled dose on Days +7 to $+8,1$ week before AHPCC. One patient received two successive VCR doses on Days +7 and +15 , with the last dose administered the day before AHPCC. There was no significant difference in patient age, sex, weight, diagnosis, or prior therapy between patients who received MC-VCR and the no-VCR cohort (Table 1). 

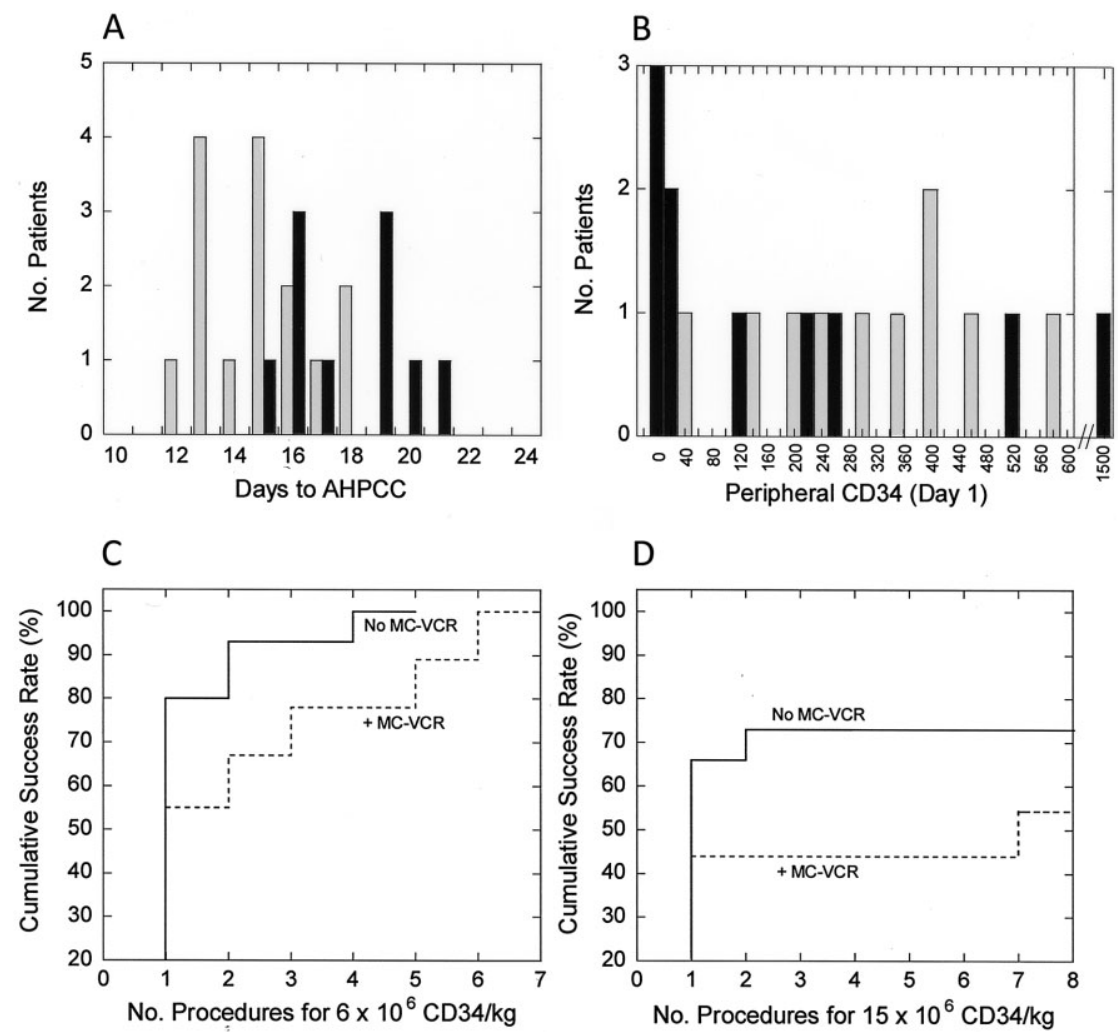

Fig. 2. CD34 mobilization in chemotherapy-mobilized patients by MC-VCR administration. (A) The number of days between the last cycle of chemotherapy and AHPCC. (B) The peripheral blood CD34 count $\left(\mathrm{CD} 34 \times 10^{6} / \mathrm{L}\right)$ on the first-day AHPCC. Data limited for patients mobilized with chemotherapy and G-CSF. Note, not all patients had a Day 1 peripheral CD34 count. ( $\square$ ) MC-VCR; $\square$ no VCR controls. (C) The cumulative success rate per procedure ${ }^{24}$ to collect at least 6 million CD34 cells $/ \mathrm{kg}$ or sufficient cells for three tandem rescues at $2 \times 10^{6} \mathrm{CD} 34 / \mathrm{kg}$. (D) The success rate per procedure to collect 15 million CD34 cells/kg or sufficient cells for three tandem rescues at $5 \times 10^{6} \mathrm{CD34} / \mathrm{kg}$. Data limited to patients mobilized with chemotherapy and G-CSF: growth factor-only mobilized patients were excluded. (- - -) MC-VCR; (一) no MC-VCR controls.

A CBC at the time of MC-VCR administration was available in seven of nine patients. Three patients were neutropenic, with a WBC count of fewer than $0.5 \times 10^{9} / \mathrm{L}$ (range, $0.1 \times 10^{9}-4.9 \times 10^{9} / \mathrm{L}$ ). All patients had a PLT count greater than $50 \times 10^{11} / \mathrm{L}$ (range, $73 \times 10^{11}-169 \times 10^{11} / \mathrm{L}$ ). No patient in the MC-VCR cohort received drugs known to increase VCR toxicity. ${ }^{19}$

\section{MC-VCR associated with delayed marrow recovery}

Patients mobilized with chemotherapy and G-CSF were tentatively scheduled for AHPCC on Day +14 after their last round of chemotherapy. AHPCC was initiated on the first day that the peripheral WBC count exceeded $5 \times 10^{9} / \mathrm{L}$. MC-VCR patients had significantly delayed marrow recovery (18 days vs. 15 days, $\mathrm{p}=0.0012$ ), with AHPCC starting on Day +19 or later in $50 \%$ of patients (Fig. 2A, Table 2). There was no correlation between the peripheral WBC count at the time of MC-VCR administration and the initiation of AHPCC ( $R=0.20$, not shown).

\section{Day 1 blood counts}

The peripheral blood counts on the first day of AHPCC were examined relative to MC- VCR administration. The median CD34 $\times 10^{6} / \mathrm{L}$ in MC-VCR patients was nearly fivefold lower than the no-VCR chemotherapy controls $\left(74.9 \times 10^{6} / \mathrm{L}\right.$ vs. $352 \times 10^{6} / \mathrm{L}$, Table 2 ), with $50 \%$ having a peripheral CD34 count of fewer than $30 \times 10^{6} / \mathrm{L}(\mathrm{p}=0.01)$. In contrast, $90 \%$ of chemotherapy-mobilized controls had a peripheral CD34 count of more than $100 \times 10^{6} / \mathrm{L}$ on Day 1 (Fig. $2 \mathrm{~B} ; \mathrm{p}=0.07$ ). The lowest mean CD34 yields were observed in patients mobilized with growth factor only (Table 2). There was no association between peripheral CD34 counts and prior radiotherapy or carboplatin administration (data not shown).

\section{MC-VCR associated with more procedures}

Among chemotherapy-mobilized patients, the no-VCR cohort averaged 1.1 procedures per patient (Table 2), with almost $70 \%$ of patients successfully collecting in one procedure $(p=0.01)$. In contrast, $33 \%$ of MC-VCR patients required four or more procedures, with an $85 \%$ decrease in median CD34 yields $\left(2.4 \times 10^{6} / \mathrm{kg}\right.$ vs. $21.5 \times 10^{6} / \mathrm{kg}$; Table 2$)$. Approximately $60 \%(14 / 25)$ of procedures yielded fewer than $3 \times 10^{6} \mathrm{CD} 34 /$ $\mathrm{kg} /$ procedure versus $12 \%(2 / 17)$ of chemotherapymobilized, no-VCR patients $(p=0.002)$. Growth factoronly mobilization was similar to MC-VCR, averaging only $2.3 \times 10^{6} \mathrm{CD} 34 / \mathrm{kg} /$ procedure (range, $0.7 \times 10^{6}-3.9 \times 10^{6}$ ), even after the addition of plerixafor (Table 2). There was no significant difference in total WBC yield, \%MNCs or $\mathrm{MNCs} / \mathrm{kg}$ yield per collection, or the final cell yield (MNCs $/ \mathrm{kg}$, CD34/kg) per mobilization cycle. As expected, there was a linear correlation between CD34/ kg yield and peripheral CD34 count ( $\mathrm{R}=0.81$, data not shown), regardless of MC-VCR administration.

\section{Mobilization failures}

Four patients required remobilization. Patients receiving MC-VCR were six times more likely to require remobilization (33\% vs. 5\%, Table 2) and accounted for $75 \%$ of all remobilizations. These patients were recollected after the 
next round of protocol-specific chemotherapy with variable success (Table 3). In two patients, MC-VCR was also administered before recollection (Fig. 1; Table 3). These two patients required daily leukapheresis for 5 consecutive days, with a mean daily yield ranging from 1.9 to 2.2 million CD34/kg. In contrast, withholding MC-VCR led to a highly successful AHPCC in a third patient $\left(37 \times 10^{6} / \mathrm{kg}\right)$.

Three patients received plerixafor. ${ }^{23}$ Two MC-VCR patients received plerixafor for two to five procedures, with a modest $40 \%$ improvement in CD34 yields $\left(1.4 \times 10^{6}\right.$ to $2.4 \times 10^{6} / \mathrm{kg} /$ procedure). Plerixafor was also administered to a patient mobilized only with G-CSF, with a fourfold increase in CD34 yield $\left(0.7 \times 10^{6} / \mathrm{kg}\right.$ to $\left.3.9 \times 10^{6} / \mathrm{kg}\right)$.

\section{Collection success rates}

The cumulative success rate to collect the minimum CD34 dose $\left(2 \times 10^{6} \mathrm{CD} 34 / \mathrm{kg}\right)$ for three tandem HPC infusions was determined for chemotherapy-mobilized patients: patients mobilized with growth factor only were excluded from the analysis. In the no-VCR cohort, 80 and $93 \%$ successfully collected at least $6 \times 10^{6} \mathrm{CD} 34 / \mathrm{kg}$ after one and two AHPCCs, respectively (Fig. 2C). In MC-VCR patients, only $55 \%$ successfully collected in one procedure and $90 \%$ after five procedures.

Because most protocols specify an optimum CD34 dose of $5 \times 10^{6} / \mathrm{kg}$ per infusion, the cumulative success rate to collect 15 million $\mathrm{CD} 34 / \mathrm{kg}$ was also determined (Fig. 2D). In the no-VCR group, $70 \%$ collected within two procedures versus $44 \%$ MC-VCR patients. In three MC-VCR patients, AHPCC was terminated at $7.5 \times 10^{6}$ to $10 \times 10^{6} \mathrm{CD} 34 / \mathrm{kg}$ due to modest collection yields, despite remobilization (one patient) and plerixafor salvage (two patients).

\section{Infusion toxicity}

Infusion toxicity is reported in $26 \%$ to $70 \%$ of patients receiving cryopreserved, autologous peripheral blood HPCs. ${ }^{30-33}$ Factors associated with infusion toxicity include small size, multiple AHPCCs, total infusion volume, DMSO dose, mobilization with growth factor only, and a high prefreeze granulocyte count. ${ }^{24,30-33}$ Because most MC-VCR patients required several AHPCCs, we reviewed the infusion and product records of chemotherapymobilized patients to determine whether MC-VCR was associated with increased infusion toxicity.

Forty-nine infusions in 18 patients were available: six patients did not receive autologous HPCs. Most patients (15/18) received three tandem HPC infusions. Mild infusion reactions (Grades 1-2) were documented in $45 \%$ of all infusions and $63 \%$ of patients: no Grade 3 or 4 toxicities were observed. ${ }^{20,33}$ Repeated infusion reactions were observed in seven patients $(7 / 15,47 \%)$. There was no significant difference in patient weight; infusion volume

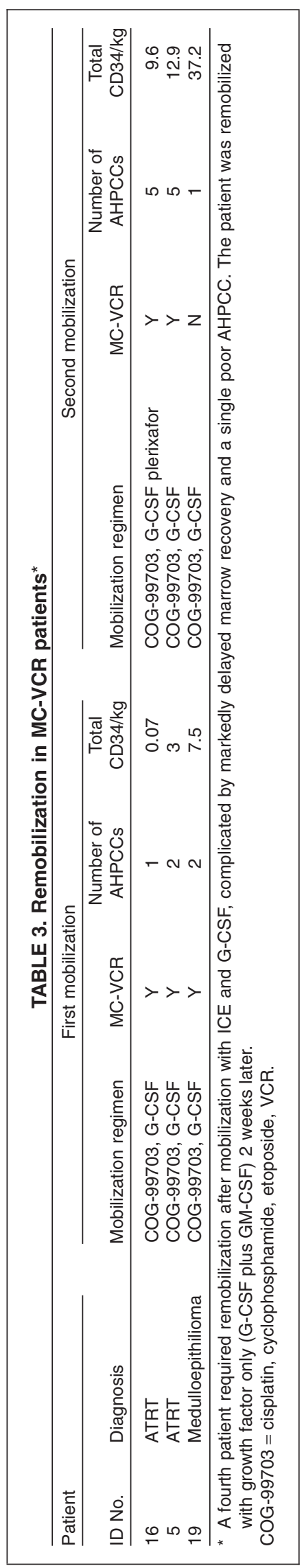




\begin{tabular}{|c|c|c|c|c|}
\hline Measure & All infusions & MC-VCR & No VCR & $p$ value \\
\hline Total number of infusions & 49 & 20 & 29 & \\
\hline Number of patients infused & 18 & 7 & 11 & 0.81 \\
\hline Patient weight $(\mathrm{kg}) \ddagger$ & $19.6 \pm 15.8(14)$ & $15.0 \pm 17.4(14.1)$ & $18.8 \pm 17.4(13.7)$ & 0.72 \\
\hline Median product volume $(\mathrm{mL}) \S$ & 100 & 100 & 100 & 0.46 \\
\hline Volume $(\mathrm{mL} / \mathrm{kg})$ & $7.4 \pm 3.5$ & $7.9 \pm 3.5$ & $7.1 \pm 3.5$ & 0.45 \\
\hline DMSO (mL/kg) & $0.73+0.35$ & $0.82+0.41$ & $0.69+0.10$ & 0.69 \\
\hline CD34 $\left(\times 10^{6} / \mathrm{kg}\right)$ & $8.92+6.23$ & $10.46 \pm 8.53$ & $7.45 \pm 3.79$ & 0.21 \\
\hline MNCs $\left(\times 10^{8} / \mathrm{kg}\right)$ & $1.21 \pm 1.00$ & $1.18 \pm 0.75$ & $1.01 \pm 0.90$ & 0.51 \\
\hline PMNs $\left(\times 10^{7} / \mathrm{kg}\right)$ & $22.22 \pm 17.2$ & $27.90 \pm 18.49$ & $17.67 \pm 14.9$ & 0.05 \\
\hline
\end{tabular}

\begin{tabular}{|c|c|c|}
\hline Measure & MC-VCR & No VCR \\
\hline Number of patients & 9 & 15 \\
\hline \multicolumn{3}{|l|}{ Leukapheresis } \\
\hline Procedure & 9,161 & 4,439 \\
\hline Laboratory & 841 & 457 \\
\hline Mean charge/patient & 10,002 & 4,897 \\
\hline \multicolumn{3}{|l|}{ Cell therapy laboratory } \\
\hline Processing & 4,749 & 2,302 \\
\hline Freezing & 1,328 & 628 \\
\hline Cell analysis & 1,577 & 764 \\
\hline Microbiology & 745 & 361 \\
\hline Mean charge/patient & 8,400 & 4,055 \\
\hline \multicolumn{3}{|l|}{ Hospitalization } \\
\hline Number (\%) of patients & $7(77.8)$ & $10(66.7)$ \\
\hline Mean number of days $\dagger$ & 3.6 & 1.5 \\
\hline Mean charge/patient† & 5,158 & 1,732 \\
\hline \multicolumn{3}{|l|}{ Total mean charge/patient } \\
\hline Without plerixafor & 23,542 & 10,900 \\
\hline With plerixafor & 28,540 & 11,757 \\
\hline \multicolumn{3}{|c|}{$\begin{array}{l}\text { * Results reported in dollars, adjusted to } 2012 \text { fiscal rate. For } \\
\text { cost analysis, patients were assigned based on their first } \\
\text { AHPCC, including four patients who underwent remobilization } \\
\text { (see Fig. 1). Charges due to G-CSF were not included due to } \\
\text { incomplete data. } \\
\text { † Mean number of days and charges for patients who required } \\
\text { hospitalization. }\end{array}$} \\
\hline
\end{tabular}

( $p=0.45$ ); or DMSO, CD34, or MNC dose per infusion although MC-VCR patients tended to receive more granulocytes $/ \mathrm{kg}$ than controls (Table 4 ). There was no difference in the infusion reactions between MC-VCR and no-VCR patients ( $40 \%$ vs. $48 \%, \mathrm{p}=0.57$ ).

\section{Cost analysis in chemotherapy-mobilized patients}

A comparison of patient charges relative to MC-VCR administration was performed (Table 5). Not surprisingly, the total mean charges for leukapheresis and cryopreservation in MC-VCR patients were twice those of controls $(p=0.014)$. There was no difference in the percentage of patients who underwent AHPCC as inpatients; however, MC-VCR patients required more hospital days per mobilization. Overall, MC-VCR administration resulted in a twofold increase in mean patient charges $(p=0.04)$. When the additional costs of plerixafor are included, mean charges increased 2.5-fold, averaging $\$ 28,000$ per patient $(p=0.009)$. If $\mathrm{G}-\mathrm{CSF}$ charges were included, the mean cost for AHPCC in MC-VCR patients could exceed $\$ 35,000$ to $\$ 40,000$.

\section{DISCUSSION}

VCR, a plant alkaloid derived from Catharanthus roseus or Madagascar periwinkle, is a common cytotoxic agent used in a wide range of adult and pediatric cancers. ${ }^{19}$ Mechanistically, VCR binds to tubulin, leading to disruptions in microtubule and mitotic spindle assembly, metaphase arrest, and apoptosis. Unlike many chemotherapeutic agents, VCR is considered marrow sparing at the doses used clinically and is often administered as a series of weekly infusions. ${ }^{19} \mathrm{VCR}$ 's major side effect is neurotoxicity, which is cumulative and dose limiting. ${ }^{19}$ Neurologic manifestations include a reversible peripheral neuritis that may present as paresthesias, myalgias, lethargy, loss of deep tendon reflexes, and neuritic pain. VCR can also result in an autonomic neuropathy with abdominal pain, constipation, and paralytic ileus. Seizures, coma, diabetes insipidus, severe marrow suppression, and death have been reported with accidental VCR overdose. ${ }^{34,35}$ Several drugs can potentiate VCR toxicity via inhibition of P-glycoprotein and hepatic cytochrome P450-CYP3A4. ${ }^{19}$

VCR is a common feature in treatment protocols for neuroblastoma and pediatric CNS tumors, which incorporate high-dose multiagent chemotherapy and HPC rescue. ${ }^{12,13,15-18,36,37}$ Because VCR is considered marrow sparing, there is no proscription against VCR administration immediately before scheduled AHPCC. However, our data indicate that MC-VCR can adversely impact AHPCC in many pediatric patients. Patients who received MC-VCR within 1 week of scheduled AHPCC had significant delays in marrow recovery, lower circulating CD34 counts, and decreased CD34 yields per procedure. As a 
result, these patients required significantly more procedures per mobilization, had higher remobilization rates, and had significantly higher patient charges. The negative impact of MC-VCR was starkly illustrated in three patients who required recollection after their next round of chemotherapy (Table 3). Withholding MC-VCR led to a single, high-yield AHPCC in one patient whereas multiple procedures and plerixafor were necessary in two patients who also received MC-VCR before their second AHPCC cycle. Surprisingly, MC-VCR was not associated with an increase in infusion toxicity, despite the increased number of procedures required in these patients.

Heavy pretreatment and radiation have both been linked to decreased CD34 yields in children. ${ }^{14,15}$ To our knowledge, this is the first report showing an adverse impact by MC-VCR on CD34 collection, despite its widespread use in pediatric malignancies. ${ }^{19}$ Unfortunately, few published trials provide a detailed analysis of AHPCC in pediatric patients. Two older studies, however, tend to support our findings. In a neuroblastoma trial conducted at the Children's Memorial Hospital in Chicago, patients received four rounds of induction chemotherapy, followed by three mobilization cycles with cyclophosphamide and VCR. ${ }^{37}$ As with our MC-VCR cohort, patients continued to receive weekly VCR immediately before AHPCC. The median CD34 yield was only $1 \times 10^{6} \mathrm{CD} 34 / \mathrm{kg}$ per procedure, with patients requiring three to 10 procedures (median, 6.7 procedures) to collect sufficient cells for three HPC rescues at 2 to 3 million CD34/kg and $35 \%$ requiring a fourth mobilization. Sung and colleagues ${ }^{15}$ reported slightly better CD34 yields in 23 pediatric CNS tumor patients, who received weekly VCR between cycles of conventional chemotherapy. Patients collected a median of $9.6 \times 10^{6} \mathrm{CD} 34 / \mathrm{kg}$ over three procedures, or a mean of $3.3 \times 10^{6} \mathrm{CD} 34 / \mathrm{kg}$ per procedure. Among patients randomized to receive two HPC rescues, $20 \%$ (3/15) were mobilization failures, collecting fewer than $5 \times 10^{6} \mathrm{C} 34 / \mathrm{kg}$.

Three additional studies support our results in our chemotherapy-mobilized controls, in which VCR is administered as part of mobilization chemotherapy without additional MC-VCR. ${ }^{38-40}$ Schroeder and coworkers $^{38}$ reported on 13 neuroblastoma patients who were mobilized with cisplatin and VCR, followed by AHPCC 2 weeks later. Patients had marrow recovery by 15 days with a mean peripheral CD34 count of $150 \times 10^{6} / \mathrm{L}$ and a mean $\mathrm{CD} 34$ yield of $8 \times 10^{6} \mathrm{CD} 34 / \mathrm{kg}$ after one to two procedures. Bensimhon and colleagues, ${ }^{39}$ in a treatment protocol for advanced neuroblastoma, also reported good CD34 yields after mobilization with VCR (Days 0 and +1 ), cyclophosphamide, and daunorubin. The median CD34 yields after one to three AHPCCs ranged from 15.7 to 30.6 million CD34/kg, depending on study cohort. Likewise, Balduzzi and colleagues ${ }^{40}$ reported high CD34 yields after mobilization with DIAVE (VCR, etoposide, idarubicin, cytosinearabinoside, and dexamethasone). Eighty percent of patients successfully collected in a single procedure, with a median peripheral CD34 count of $80 \times 10^{6} \mathrm{CD} 34 / \mathrm{L}$ and median CD34 yield of 11 million CD34/kg.

Despite its reputation as marrow sparing, ${ }^{19} \mathrm{VCR}$ is often associated with mild to severe marrow suppression at the doses and schedule used clinically. Zeltzer and coworkers $^{41}$ reported Grade 3 and 4 hematologic toxicity in $40 \%$ to $50 \%$ of medulloblastoma patients receiving standard weekly VCR. Leukopenia was the most common toxicity, followed by moderate thrombocytopenia and anemia. VCR appears to target colony-forming unit (CFU)-GM while earlier pluripotent progenitors (CFUGEMM) appear relatively resistant. ${ }^{42,43}$ In murine models, VCR leads to an abrupt, $70 \%$ to $80 \%$ decrease in circulating CFUs within 24 hours that persists for several days. ${ }^{44}$ In ex vivo purging protocols, low-dose VCR (1-3 $\mathrm{gg} / \mathrm{mL})$ was associated with a 50\% decrease in CFU-GM whereas higher doses $(100 \mu \mathrm{g} / \mathrm{mL})$ resulted in $90 \%$ ablation of CFU-GM. ${ }^{41,42,45,46}$

In summary, pediatric CNS patients receiving MC-VCR immediately before AHPCC had delayed marrow recovery with lower mean circulating CD34 counts and CD34 yields. As a consequence, these patients often required more procedures and more days of growth factor and were at higher risk for remobilization and plerixafor salvage. Our results are limited by the retrospective design of the study, small patient numbers, and mix of study patients receiving different chemotherapy and mobilization regimens. However, the majority of patients $(20 / 24$, Table 1) were treated per three COG studies with similar adjuvant therapy and early AHPCCs. Since 2010, our policy is to hold MC-VCR within 10 to 14 days before scheduled AHPCC for all pediatric patients. Given the widespread use of weekly VCR in pediatric malignancies, we propose that future study protocols involving autologous HPC rescue consider withholding MC-VCR before AHPCC.

\section{CONFLICT OF INTEREST}

The authors report no conflicts of interest or funding sources.

\section{REFERENCES}

1. Central Brain Tumor Registry of the United States (CBTRUS). CBTRUS statistical report. Primary brain and central nervous system tumors diagnosed in the United States in 2004-2008 (revised March 23, 2012). [cited 2012 Jun 20]. Available from: http://www.cbtrus.org/2012-NPCR -SEER/CBTRUS_Report_2004-2008_3-23-2012.pdf

2. Massimino M, Giangaspero F, Garre ML, et al. Childhood medulloblastoma. Crit Rev Oncol Hematol 2011;79:65-83.

3. Varan A. Risk-adapted chemotherapy in childhood medulloblastoma. Expert Rev Anticancer Ther 2011;11:771-80. 
4. Wright KD, Gajjar A. New chemotherapy strategies and biological agents in the treatment of childhood ependymoma. Childs Nerv Syst 2009;25:1275-82.

5. Bourdeaut F, Miquel C, Alapetite C, et al. Medulloblastomas: update on a heterogenous disease. Curr Opin Oncol 2011;23:630-7.

6. Grill J, Bergthold G, Ferreira C. Pediatric ependymomas: will molecular biology change patient management? Curr Opin Oncol 2011;23:638-42.

7. Hilden JM, Meerbaum S, Burger P, et al. Central nervous system atypical teratoid/rhabdoid tumor: results of therapy in children enrolled in a registry. J Clin Oncol 2004;22:2877-84.

8. Packer RJ, Gajjar A, Vezina G, et al. Phase III study of craniospinal radiation therapy followed by adjuvant chemotherapy for newly diagnosed average-risk medulloblastoma. J Clin Oncol 2006;24:4202-8.

9. Rutkowski S, Bode U, Deinlein F, et al. Treatment of early childhood medulloblastoma by postoperative chemotherapy alone. N Engl J Med 2005;352:978-86.

10. Massimino M, Cohen KJ, Finlay JL. Is there a role for myeloablative chemotherapy with autologous hematopoietic cell rescue in the management of childhood highgrade astrocytomas? Pediatr Blood Cancer 2010;54: 641-3.

11. Gilman AL, Jacobsen C, Bunin N, et al. Phase 1 study of tandem high-dose chemotherapy with autologous peripheral blood stem cell rescue for children with recurrent brain tumors: a pediatric blood and marrow transplant consortium study. Pediatr Blood Cancer 2011;57:506-13.

12. Chi SN, Gardner SL, Levy AS, et al. Feasibility and response to induction chemotherapy intensified with high-dose methotrexate for young children with newly diagnosed high-risk disseminated medulloblastoma. J Clin Oncol 2004;22:4881-7.

13. Gajjar A, Chintagumpala M, Ashley D, et al. Risk-adapted craniospinal radiotherapy followed by high-dose chemotherapy and stem-cell rescue in children with newly diagnosed medulloblastoma (St Jude Medullobastoma-96): long-term results from a prospective, multicenter trial. Lancet Oncol 2006;7:813-20.

14. Sung KW, Yoo KH, Chung EH, et al. Successive double high-dose chemotherapy with peripheral blood stem cell rescue collected during a single leukapheresis round in patients with high-risk pediatric solid tumors: a pilot study in a single center. Bone Marrow Transplant 2003;31:447-52.

15. Sung KW, Yoo KH, Cho EJ, et al. High-dose chemotherapy and autologous stem cell rescue in children with newly diagnosed high-risk or relapsed medulloblastoma or supratentorial primitive neuroectodermal tumor. Pediatr Blood Cancer 2007;48:408-15.

16. Children's Oncology Group. COG-99701: Carboplatin and vincristine plus radiation therapy followed by adjuvant chemotherapy in treating young patients with newly diagnosed CNS embryonal tumors. 1999. [cited 2012 Jun 20].
Available from: http://www.clinicaltrials.gov/ct2/show/ NCT00003203

17. Children's Oncology Group. COG-99703: Chemotherapy plus peripheral stem cell transplantation in treating infants with malignant brain or spinal cord tumors. 1999. [cited 2012 Jun 20]. Available from: http://www.clinicaltrials.gov/ ct2/show/NCT00003141

18. National Cancer Institute. COG-ACNS0333: Phase III study of induction therapy comprising vincristine, high-dose methotrexate, leucovorin calcium, etoposide, cisplatin, and cyclophosphamide followed by 3-dimensional conformal radiotherapy and high-dose consolidation therapy comprising carboplatin, thiotepa, and autologous peripheral blood stem cell rescue in pediatric patients with atypical teratoid/rhabdoid tumors of the central nervous system. 2008. [cited 2012 Jun 20]. Available from: http://www .clinicaltrials.gov/ct2/show/NCT00653068

19. Moore A, Pinkerton R. Vincristine: can its therapeutic index be enhanced? Pediatr Blood Cancer 2009;53: 1180-7.

20. National Cancer Institute. Common terminology criteria for adverse events and common toxicity criteria v4.0. 2009. [cited 2012 Jun 20]. Available from: http://evs.nci.nih.gov/ ftp1/CTCAE/CTCAE_4.03_2010-06-14_QuickReference _5x7.pdfCTC-NCIclassification

21. Saito R, Kumabe T, Sonoda Y, et al. Combination chemotherapy with ifosfamide, cisplatin, and etoposide for medulloblastoma: single-institute experience and differences in efficacy for subgroups of medulloblastoma. Childs Nerv Syst 2011;27:1399-406.

22. Barone G, Maurizi P, Tamburrini G, et al. Role of temozolomide in pediatric brain tumors. Childs Nerv Syst 2006;22:652-61.

23. Li J, Hamilton E, Vaugn L, et al. Effectiveness and cost analysis of "just-in-time" salvage plerixafor administration in autologous transplant patients with poor stem cell mobilization kinetics. Transfusion 2011;51:2175-82.

24. Cooling L, Hoffmann S, Herrst M, et al. A prospective randomized trial of two popular mononuclear cell collection sets for autologous peripheral blood stem cell collection in multiple myeloma. Transfusion 2010;50:100-19.

25. Gidron A, Verma A, Doyle M, et al. Can the stem cell mobilization technique influence CD34+ cell collection efficiency of leukapheresis procedures in patients with hematologic malignancies? Bone Marrow Transplant 2005; 35:243-6.

26. Sutherland DR, Anderson L, Keeney M, et al. The ISHAGE guidelines for CD34+ cell determination by flow cytometry. International Society for Hematotherapy and Graft Engineering. J Hematother 1996;5:213-26.

27. Food and Drug Administration. Code of Federal Regulations, General Biological Product Standards: 21 CFR 610.12. 2011.

28. Jakacki R, Burger P, Zhou T, et al. Outcome for metastatic $\mathrm{M}+$ ) medulloblastoma treated with carboplatin during 
craniospinal radiotherapy (CSRT) followed by cyclophosphamide and vincristine: preliminary result of COG 99701 [abstract]. J Clin Oncol 2007;25:2017.

29. Coughlin DT, Richmond RC. Biologic and clinical developments of cisplatin combined with radiation: concepts, utility, projections for new trials and the emergence of carboplatin. Semin Oncol 1989;16:31-43.

30. Cooling L, Gorlin JB. Transfusion reactions associated with hematopoietic progenitor cell reinfusion. In: Poposvsky MA, editor. Transfusion reactions. 3rd ed. Bethseda, MD: American Association of Blood Banks; 2007. p. 301-30.

31. Okamoto Y, Takaue Y, Saito S, et al. Toxicities associated with cryopreserved and thawed peripheral blood stem cell autografts in children with active cancer. Transfusion 1993; 33:578-81.

32. Perseghin P, Balduzzi A, Bonanomi S, et al. Infusionrelated side-effects in children undergoing autologous hematopoietic stem cell transplantation for acute leukemia. Bone Marrow Transplant 2000;26:116-8.

33. Calmels B, Lemarie C, Esterni B, et al. Occurrence and severity of adverse events after autologous hematopoietic progenitor cell infusion are related to the amount of granulocytes in the apheresis product. Transfusion 2007; 47:1268-75.

34. Schulmeister L. Preventing vincristine sulfate medication errors. Oncol Nurs Forum 2004;31:E90-6.

35. Trinkle R, Wu JK. Errors involving pediatric patients receiving chemotherapy: a literature review. Med Pediatr Oncol 1996;26:344-51.

36. Pearson AD, Pinkerton CR, Lewis IJ, et al. High-dose rapid and standard induction chemotherapy for patients aged over 1 year with stage 4 neuroblastoma: a randomized trial. Lancet Oncol 2008;9:247-56.

37. Kletzel M, Katzenstein HM, Haut PR, et al. Treatment of high-risk neuroblastoma with triple-tandem high-dose therapy and stem cell rescue: results of the Chicago pilot II study. J Clin Oncol 2002;20:2284-92.

38. Schroeder H, Kamperis K, Grunnet N, et al. Prediction of target CD34 positive cells following leukopheresis in children with neuroblastoma. Pediatr Blood Cancer 2006; 46:786-92.

39. Bensimhon P, Villablanca JG, Sender LS, et al. Peripheral blood stem cell support for multiple cycles of dose intensive induction therapy is feasible with little risk of tumor contamination in advanced stage neuroblastoma: a report from the Childrens Oncology Group. Pediatr Blood Cancer 2010;54:596-602.

40. Balduzzi A, Perseghin P, Dassi M, et al. Peripheral blood stem cell collection in children with acute leukemia: effectiveness of the 'DIAVE' mobilizing regimen. Bone Marrow Transplant 2002;30:413-6.

41. Zeltzer PM, Boyett JM, Finlay JL, et al. Metastasis stage, adjuvant treatment, and residual tumor are prognostic factors for medulloblastoma in children: conclusions from the children's cancer group 921 randomized phase III study. J Clin Oncol 1999;17:832-45.

42. Kapoor N, Keever CA, Leong N, et al. Effects of ex vivo treatment with methylprednisolone and vincristine on bone marrow lymphohematopoietic cells. In: Worthington-White DA, Gee AP, Gross S, editors. Progress in clinical and biological research, Vol. 377: Advances in bone marrow purging and processing. New York: WileyLiss; 1992. p. 49-56.

43. Lanfranchi A, Andolina M, Tettoni K, et al. Functional depletion of $\mathrm{T}$ cells by vincristine and methylprednisolone as an invitro model for the prevention of graft versus host disease. Haematologica 1992;77:11-5.

44. Necas E, Ponka P, Neuwirt J. Effect of some cytostatics on the haemopoietic stem cells (CFUs) in blood. Cancer Chemother Pharmacol 1979;2:215-9.

45. Jones RJ, Miller CB, Zehnbauer BA, et al. In vitro evaluation of combination drug purging for autologous bone marrow transplantation. Bone Marrow Transplant 1990;5:301-7.

46. Rowley SD, Miller CB, Piantadosi S, et al. Phase I study of combination drug purging for autologous bone marrow transplantation. J Clin Oncol 1991;9:2210-8. 